\title{
Landmark studies on the glucagon subfamily of GPCRs: from small molecule modulators to a crystal structure
}

\author{
De-hua YANG, Cai-hong ZHOU, Qing LIU, Ming-wei WANG* \\ The National Center for Drug Screening and the CAS Key Laboratory of Receptor Research, Shanghai Institute of Materia Medica, \\ Chinese Academy of Sciences (CAS), Shanghai 201203, China
}

The glucagon subfamily of class B G-protein-coupled receptors (GPCRs) has been proposed to be a crucial drug target for the treatment of type 2 diabetes. The challenges associated with determining the crystal structures of class B GPCRs relate to their large amino termini and the lack of available small molecule ligands to stabilize the receptor proteins. Following our discovery of non-peptidic agonists for glucagon-like peptide-1 receptor (GLP-1R) that have therapeutic effects, we initiated collaborative efforts in structural biology and recently solved the three-dimensional (3D) structure of the human glucagon receptor (GCGR) 7-transmembrane domain, providing in-depth information about the underlying signaling mechanisms. In this review, some key milestones in this endeavor are highlighted, including discoveries of small molecule ligands, their roles in receptor crystallization, conformational changes in transmembrane domains (TMDs) upon activation and structure-activity relationship analyses.

Keywords: class B GPCR; GLP-1R; GCGR; small molecule modulators; crystal structure; type 2 diabetes mellitus

Acta Pharmacologica Sinica (2015) 36: 1033-1042; doi: 10.1038/aps.2015.78; published online 17 Aug 2015

\section{Introduction}

The prevalence of diabetes is increasing worldwide. Most cases are type 2 diabetes mellitus (T2DM), which parallels a marked lifestyle transition and a worldwide epidemic of obesity in both developed and developing countries. Last year, the American Diabetes Association announced that 29.1 million Americans, representing 9.3\% of the population, had diabetes in 2012, whereas in China it affected 113.9 million people, or $11.6 \%$ of the Chinese adult population in $2010^{[1,2]}$. These large national surveys indicate that diabetes has become a major public health problem, as well as a leading cause for disability and mortality in modern societies. The cardinal symptoms of T2DM are hyperglycemia and subsequent complications, which result in the main therapeutic strategies relying heavily on the management of hyperglycemia, including the use of metformin, sulfonylurea, thiazolidinedione, insulin, and inhibitors or modulators of sodium glucose cotransporter 2 (SGLT2), dipeptidyl peptidase 4 (DPP-4) and glucagon-like peptide-1 receptor (GLP-1R) agonists. For these indications, target-based drug discovery has been a focal point

\footnotetext{
* To whom correspondence should be addressed. E-mail mwwang@simm.ac.cn

Received 2015-05-15 Accepted 2015-06-24
}

of research for decades ${ }^{[3]}$.

G protein-coupled receptors (GPCRs), of which there are more than 800 , have heptahelical transmembrane domains (TMDs) and represent the richest source of therapeutic targets for the pharmaceutical industry ${ }^{[4]}$. They mediate cellular responses to external stimuli via their extracellular face; they transmit this extracellular signal and elicit various activities in the cell through structural transitions of their intracellular face ${ }^{[5]}$. This signal transduction is realized by $G$ proteins, which are coupled to second messengers, such as cAMP, inositol 1,4,5-trisphosphate (IP3), and $\mathrm{Ca}^{2+}$, and perform vital functions in vision, olfactory perception, metabolism, the endocrine system, neuromuscular regulation and the central nervous system $(\mathrm{CNS})^{[6]}$. The GPCR family is divided into five main subfamilies - rhodopsin (class A), secretin (class B), glutamate (class C), frizzled (class F) and adhesion (others) ${ }^{[7]}$ - endowing the cell with remarkably versatile functions. Understanding the three-dimensional (3D) structures of GPCRs will help elucidate their functionalities. However, the highly conserved hydrophobic core of GPCRs and its inherent flexibility cause enormous difficulties for protein purification and crystallization. To date, the crystal structures of 23 class A GPCRs have been determined ${ }^{[8-10]}$, increasing our knowledge of the molecular mechanisms of ligand binding and receptor 
activation and facilitating structure-based drug design.

In addition to a seven-transmembrane fold similar to that in class A GPCRs, class B receptors feature a large extracellular $\mathrm{N}$-terminal region, which is responsible for binding to peptide ligands of 30-40 amino acid residues. The extracellular domains (ECDs) of class B GPCRs have been structurally elucidated in complex with their cognate ligands, revealing some common features of peptide hormone recognition ${ }^{[11]}$; however, it has been difficult to obtain crystal structures of full-length class B GPCRs, owing to considerable technical hurdles in receptor production, purification, and protein stability and homogeneity (including difficulties in finding optimal protein constructs, buffer conditions, lipids, detergents and highaffinity small molecule modulators). Structures of the TMDs of class B GPCRs were not available until the recent publication of the structures of human glucagon receptor (GCGR) and human corticotropin-releasing factor receptor $1\left(\mathrm{CRF}_{1} \mathrm{R}\right)^{[12,13]}$. In this review, we focus on the glucagon subfamily of class $B$ GPCRs and summarize the key milestones in studies on the structure and function of GCGR and GLP-1R, including discoveries of small molecule ligands, their roles in the receptors' crystallization, the conformational changes in TMDs upon activation and structure-activity relationship (SAR) analyses.

\section{Class B GPCRs}

The class B GPCRs are a family of receptors with 15 members that interact with a variety of therapeutically relevant peptide hormones, including secretin, glucagon, GLPs, vasoactive intestinal peptide (VIP), pituitary adenylate cyclase-activating peptide (PACAP), growth hormone-releasing factor (GRF), gastric inhibitory polypeptide or glucose-dependent insulinotropic polypeptide (GIP), corticotropin-releasing factor (CRF), parathyroid hormone $(\mathrm{PTH})$ and calcitonin ${ }^{[11,14-20]}$. When developing therapeutics, a major drawback of these endogenous peptides is their very short half-lives, which result from rapid degradation ${ }^{[21]}$. Therefore, the development of stable non-peptidic agonists for class B GPCRs is an important mission. This is in marked contrast to class A GPCRs, for which antagonists rather than agonists have been actively pursued ${ }^{[8]}$. Despite extensive efforts made by the pharmaceutical industry, there has been little success in developing drug-like nonpeptidic ligands for class B GPCRs.

Each class B GPCR consists of a large N-terminal disulfidelinked ECD, and the crystal structures of ECDs bound to several cognate peptide ligands have revealed a consensus mechanism for hormone binding ${ }^{[11]}$. ECD binding invokes $a$-helix formation by the hormone, which in turn leads to receptor activation. Currently, 9 of the 15 class B GPCR ECD structures have been determined, all showing that the C-terminal $a$-helix of the ligand binds to the $\beta$-sheet of the ECD, with the exception of PACAP, which displayed a bend at the Ala18 resi$\mathrm{du}^{[22-32]}$. These studies provide important information about the structural basis of ligand recognition and selectivity.

\section{GCGR and GLP-1R}

The glucagon subfamily of class B GPCRs includes GCGR,
GLP-1R, glucagon-like peptide-2 receptor (GLP-2R) and GIP receptor (GIPR), whose natural ligands share a high degree of sequence homology at their amino termini. This subfamily of receptors plays important roles in regulating glucose homeostasis, with the ligand glucagon acting to maintain blood glucose levels via the conversion of glycogen to glucose and incretins reducing blood glucose levels primarily through stimulating the release of insulin. These receptors are of considerable interest as targets in the treatment of metabolic disorders. In particular, a number of GLP-1R peptidic agonists, which are resistant to enzymatic breakdown by dipeptidyl peptidase-4 (DPP-4), have been shown to be highly effective in the treatment of T2DM and obesity, not only lowering blood glucose but also eliciting weight loss ${ }^{[33]}$.

GCGR is a 485 amino acid protein with a high affinity for glucagon binding. It has been identified in the liver, kidney, intestinal smooth muscle, brain and adipose tissue ${ }^{[34]}$. GCGR is also expressed in pancreatic islet $\beta$-cells, which are involved in the regulation of insulin secretion ${ }^{[35]}$. In addition to its link to intra-hepatic glucose metabolism, GCGR expression is positively regulated by glucose and negatively regulated by glucagon and agents that increase intracellular cAMP ${ }^{[36]}$. Experiments using GCGR and GLP-1R antagonists suggest that glucagon activates $\beta$-cell signaling pathways via both receptors ${ }^{[37]}$. Disruption of GCGR activity in $\mathrm{Gcgr}^{-/-}$mice led to a significant increase in total pancreatic weight, marked islet a-cell hyperplasia and an elevation of circulating glucagon and GLP-1 levels, accompanied by multiple defects in the development of islet cell phenotypes ${ }^{[38]}$. These results give important insights into the role of GCGR in pancreatic islet $\beta$-cells beyond the control of hepatic glucose production.

Human GLP-1R consists of 463 amino acids and exhibits approximately $47 \%$ sequence identity with GCGR. It has been localized to multiple tissues and cell types in the pancreas, central and peripheral nervous systems, gastrointestinal tract, cardiovascular system, kidney and lung ${ }^{[39]}$. Its pancreatic localization is primarily in $\beta$-cells, and the natural peptide ligand is GLP-1, whose importance for regulating postprandial blood glucose levels has been known for decades. Likewise, impairment of incretin function in T2DM is widely accepted and has led to the development of stable GLP-1 analogues for T2DM treatment ${ }^{[40,41]}$. In pancreatic $\beta$-cells, GLP-1 exerts its insulinotropic action via GLP-1R, which leads to the initiation of numerous intracellular signaling pathways, such as the $\mathrm{Ga}_{\mathrm{s}}$-mediated cAMP pathway, calcium mobilization and MAP kinase activation ${ }^{[42]}$. A major goal for the treatment of T2DM has been the development of orally active, non-peptidic GLP-1R agonists ${ }^{[43,44]}$. Although lead compounds have been reported in the literature, progress has been slow to date.

\section{Other subfamily members}

The human GLP-2R gene is localized on chromosome 17p13.3 and shares approximately $50 \%$ sequence identity with GLP$1 \mathrm{R}^{[45]}$. It is expressed predominantly in the gastrointestinal tract, and its biological actions have been implicated in gut injury, short bowel syndrome and adaptive mucosal responses 
to re-feeding ${ }^{[45]}$. Similar to GLP-1R, GLP-2R also plays important roles in glucose intolerance and hepatic insulin resistance ${ }^{[46]}$. The elimination of GLP-2R signaling in obese mice impaired the normal islet adaptive responses required to maintain glucose homeostasis ${ }^{[46]}$. To date, only one small molecule modulator, which was determined to be of ago-allosteric nature, has been reported for this receptor ${ }^{[47]}$. GIPR is widely expressed in the pancreas, stomach, small intestine, adipose tissue, adrenal cortex, pituitary gland, heart, testis, endothelial cells, bone, trachea, spleen, thymus, lung, kidney, thyroid and several regions of the CNS. It is thought that this hormone is involved in physiological processes such as bone quality ${ }^{[48]}$, memory formation and the control of appetite ${ }^{[49,50]}$, as well as the pathogenesis of obesity and insulin resistance ${ }^{[51]}$. While GLP-2R and GIPR might be crucial for understanding obesity and diabetes, little research has been conducted in terms of chemical and structural biology. Therefore, this review will focus on GCGR and GLP-1R.

\section{Small molecule GLP-1R modulators}

Compounds 1 (T-0632) ${ }^{[52]}$ and 2 (catechin, see Table 1$)^{[53]}$ were reported to be GLP-1R antagonists. Compound 1, originally identified as a cholecystokinin receptor 1 (CCK1) antagonist, is a non-competitive antagonist of human GLP-1R with low micromolar potency and is presumably capable of binding to the ECD (a large independently folded globular ectodomain at the N-termini of class B GPCRs) of GLP- $1 R^{[52]}$. However, its low affinity for GLP-1R combined with its sub-nanomolar CCK1 antagonist activity makes it not a useful molecular tool. Compound $\mathbf{2}$ is a polyphenolic natural product that functionally acts as a selective negative allosteric modulator of GLP$1 \mathrm{R}^{[53]}$. It displays signaling bias in a peptide-specific manner. In calcium mobilization assays, catechin had no effect on agonist-mediated signaling; however, in cAMP accumulation assays, catechin acted as a negative modulator of both GLP- $1_{(7-}$ ${ }_{36} \mathrm{NH}_{2}$ and GLP-1 $1_{(1-36)} \mathrm{NH}_{2}$. Furthermore, the potency of GLP$1_{(7-37)}$ in stimulating cAMP production was also significantly reduced (8-fold) in the presence of catechin, whereas cAMP responses to GLP-1 $1_{(1-37)}$, exendin-4 and oxyntomodulin were unaltered.

Compounds 3-8 were reported to be GLP-1R agonists. Quinoxaline derivatives, represented by compounds 3 and $\mathbf{4}$, were discovered by Novo Nordisk ${ }^{[5]}$. An initial screening of 500000 small molecules in a competition-binding assay did not find any useful hits. A subsequent functional screening of 250000 chemically diverse compounds and follow-up SAR studies led to the discovery of these quinoxaline derivatives. Compound $\mathbf{4}$ was characterized as a selective ago-allosteric GLP-1R agonist as its activity could not be blocked by exen$\operatorname{din}_{9-39}$. It increased the binding affinity of both GLP-1 and oxyntomodulin for GLP-1R and promoted glucose-dependent insulin secretion in wild-type mouse islets but not in GLP-1R knockout mice.

Then, a series of pyrimidine derivatives exemplified by compound 5 (BETP) was discovered, which have key structural differences from the previously reported quinoxalines. The pyrimidines require both trifluoromethyl and sulfonyl groups and an electron deficient heterocycle for strong activity, whereas the quinoxalines require one of the functional groups and an electron-rich ring system. Compound $\mathbf{5}$ demonstrated dose-dependent activities in both cAMP accumulation and insulin secretion assays. Similar to the quinoxalines, BETP exhibited agonist and positive allosteric activities for GLP-1R, and its agonist actions could not be blocked by exendin ${ }_{9-39}{ }^{[55]}$. Compound 6 is a GLP-1R agonist with an oxadiazoanthracene skeleton ${ }^{[56,57]}$. It showed a nanomolar potency for GLP-1R in cAMP assays, and it stimulated glucose-dependent insulin secretion by rodent islets and improved glucose excursion in an oral glucose tolerance test ${ }^{[58,59]}$.

Full GLP-1R agonists, represented by compound 7 (Boc5) and its cyclopentyl derivative (S4P, 8), were reported by our group in $2007^{[43]}$. They are a new class of cyclobutanes with four chiral carbons. The X-ray crystal structure of compound 7 indicates that it adopts an anti head-to-tail 1,2-cis-2,3-cis-3,4cis configuration in which the four side chains of the core point in the same direction, similar to the four legs on a stool ${ }^{[60]}$. The bioactivities of compound 7 and its three steric isomers differ significantly in both GLP-1R binding and MRE/CRE-driven reporter gene assays, with compound 7 , the most potent GLP$1 \mathrm{R}$ agonist, exhibiting as high as $96.7 \%$ efficacy relative to the native peptide, GLP-1. It is also a selective GLP-1R agonist because it does not activate reporter gene activity of other related GPCRs, such as GLP-2R, GCGR and GIPR ${ }^{[43,61]}$. Following chronic intraperitoneal administration to diabetic $d b / d b$ mice, compound 7 lowered HbA1c, reduced food intake, decreased body weight and enhanced insulin secretion ${ }^{[61,62]}$. These therapeutic effects were also reproduced by a derivative of compound 7 called WB4-24 (an isobutyryl derivative) ${ }^{[60]}$. However, the poor oral bioavailability and undesirable structural characteristics of these compounds make them undruggable (this class of molecules violates all of the Lipinsky and Veber rules) ${ }^{[63]}$.

\section{Small molecule GCGR modulators}

A series of $\beta$-alanines, represented by compounds 9-11 (Table 2), were reported to be ligands for both GLP-1R and GCGR. Four libraries containing 1056 compounds were designed to avoid the potential toxicity of the 2-chloropyridyl group in compound $9^{[64]}$. The results were as follows: 1 ) the 2-chloropyridyl group could be replaced by other aromatic groups such as benzothiophene; 2) the large biphenylpropyl group could be replaced by smaller sized and lower lipophilicity groups such as 4-tert-butylbenzyl; 3) the central amide could be replaced by urea, keeping the important binding moieties together in a suitable geometry for the binding of the ligand to the receptor; and 4) compounds with either small electronwithdrawing or larger lipophilic groups in the para position of the distal phenyl moiety increased the potency.

This led to the discovery of compounds $\mathbf{1 0}$ and $\mathbf{1 1}$, both of which are orally available in dogs and capable of decreasing blood glucose levels in diabetic animals, with $\mathbf{1 1}$ having better pharmacokinetic properties. Their selectivity for GLP-1R 
Table 1. Small molecule modulators for glucagon-like peptide-1 receptors.

№ Chemical structure

2<smiles>Oc1cc(O)c2c(c1)O[C@H](c1ccc(O)c(O)c1)C(O)C2</smiles>

Selective and negative

(Catechin)<smiles>Cc1nnc(Sc2nc3cc(Cl)c(Cl)cc3nc2C(F)(F)F)s1</smiles><smiles>CC(C)(C)Nc1nc2cc(Cl)c(Cl)cc2nc1S(C)(=O)=O</smiles>

5<smiles>CCS(=O)c1nc(-c2cccc(OCc3ccccc3)c2)cc(C(F)(F)F)n1</smiles>

Agonist

3 allosteric modulator

Reference

Non-competitive antagonist$$
\mathrm{F}
$$

Selective ago-allosteric agonist

6<smiles>CCC(c1ccccc1)N1Cc2cc3c(cc2CC1C(=O)N[C@H](Cc1ccc(-c2ccc(C#N)cc2)cc1)C(=O)O)N(C)C(=O)C(c1ccc(OCc2ccc(Cl)c(Cl)c2)cc1)O3</smiles>

Positive allosteric agonist

Agonist

[56-59]

7

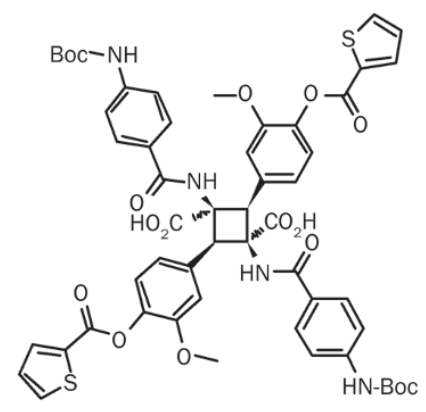

Full agonist

$[43,60-62]$ 


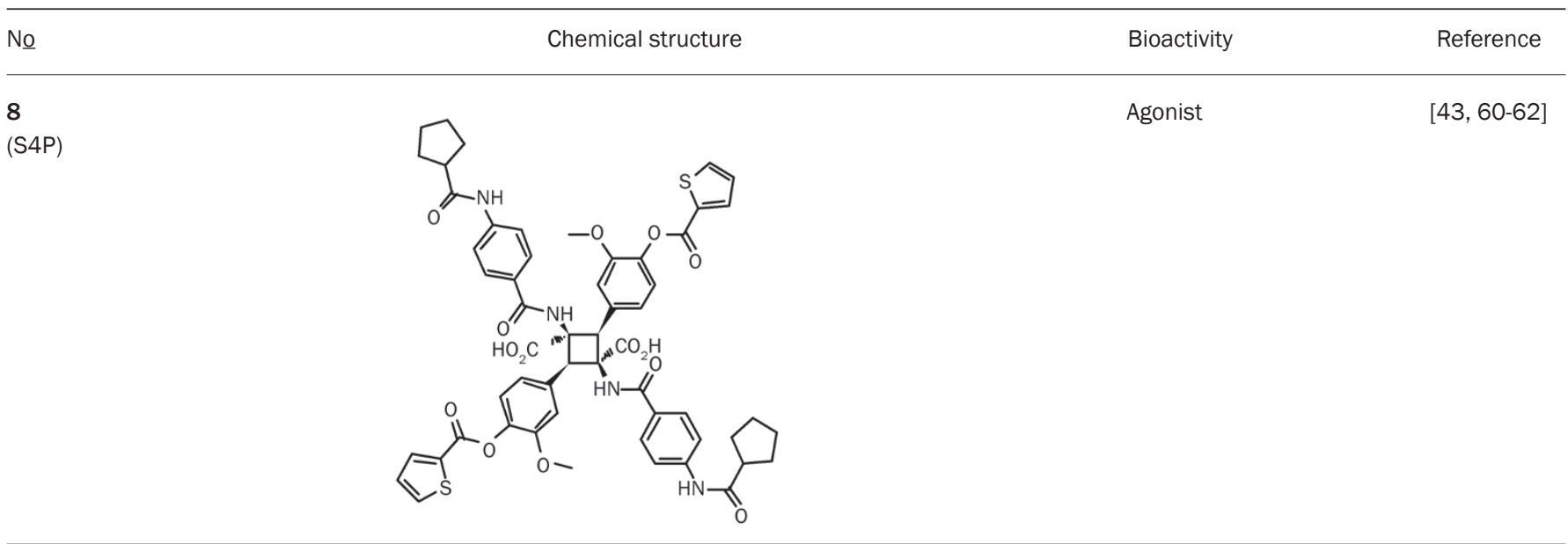

and GCGR was also studied; both compounds displayed weak binding affinities for GLP-1R $\left(\mathrm{IC}_{50}=1 \mu \mathrm{mol} / \mathrm{L}\right.$ for $\mathbf{1 0}$ and 4.9 $\mu \mathrm{mol} / \mathrm{L}$ for 11) with 11 having 180-fold selectivity for GCGR over GLP-1R.

Cascieri et al developed a series of triarylimidazole and triaryl-pyrrole derivatives, represented by compound $\mathbf{1 2}$ (L-168,049), with selective binding affinity for GCGR. Compound 12 inhibited the binding of radiolabeled glucagon to GCGR with an $\mathrm{IC}_{50}$ value of $3.7 \mathrm{nmol} / \mathrm{L}$, without any effects on the binding of labeled GLP-1 to GLP-1R at concentrations up to $10 \mu \mathrm{mol} / \mathrm{L}^{[65]}$. Acylated aminothiophene-3-nitrile derivatives, represented by compound 13, were reported by Duffy et al to be GCGR antagonists. Compound $\mathbf{1 3}$ displayed moderate binding $\left(\mathrm{IC}_{50}=181 \mathrm{nmol} / \mathrm{L}\right)$ and cAMP accumulation activities $\left(\mathrm{IC}_{50}=129 \mathrm{nmol} / \mathrm{L}\right)$. Further structural modifications led to the development of compound 14, which improved potencies for both receptor binding $\left(\mathrm{IC}_{50}=89 \mathrm{nmol} / \mathrm{L}\right)$ and cAMP accumulation $\left(\mathrm{IC}_{50}=34 \mathrm{nmol} / \mathrm{L}\right)^{[66]}$.

As a continuation, Lee et al incorporated a cyclic core (pyrrolidine or cyclopentane) to restrain the conformation and developed compound $\mathbf{1 5 ^ { [ 6 7 ] }}$, which was disclosed as a novel GCGR antagonist. They replaced the central phenyl ring with a pyrimidine to obtain two enantiomers, (+) 16 and (-) 16. Both of these compounds were resistant to oxidative metabolism in human, rat and dog liver microsomes in vitro. In vivo pharmacokinetic studies on (+) 16 and (-) 16 were also conducted in Wistar-Han rats and in dogs. However, a high plasma clearance, especially for $(+) \mathbf{1 6}\left(\mathrm{Cl}=56.7 \mathrm{~mL} \cdot \mathrm{min}^{-1}\right.$. $\mathrm{kg}^{-1}$ ), was observed in rats. Re-examination in bile duct-cannulated rats revealed that biliary excretion was a major route for drug elimination, even though $40 \%-45 \%$ of the dosed parent compounds was unchanged. Interestingly, a significant difference in clearance was observed in dogs $\left[25.8 \mathrm{~mL} \cdot \mathrm{min}^{-1}\right.$. $\mathrm{kg}^{-1}$ for (+) 16 and $2.7 \mathrm{~mL} \cdot \mathrm{min}^{-1} \cdot \mathrm{kg}^{-1}$ for (-) 16], which may be caused by an enantio-specific interaction with the biliary efflux transporter(s) in dogs ${ }^{[68]}$.

Further structural modification was carried out by introduc- ing spiroimidazolone to obtain compound $\mathbf{1 7}$ and its bioisostere compound 18 (a tetrazole derivative, SCH 900822), and by introducing a pyrazole to obtain compound 19. Compound 18 exhibited better selectivity, and oral dosing with 18 lowered 4-h fasting and 24-h non-fasting glucose levels in dietinduced obese (DIO) mice and 8-h fasting glucose levels in streptozotocin-induced type 2 diabetic mice ${ }^{[69]}$. Compound 19 (MK-0893) was reported to be a reversible and competitive GCGR antagonist that does not cross react with other class $B$ GPCRs, including GIPR, PAC1, GLP-1R, VPAC1 and VPAC2. In insulin-resistant $o b / o b$ mice, compound 19 lowered blood glucose levels by up to $39 \%$ with acute oral administration, whereas in DIO mice receiving chronic oral treatment, compound 19 decreased blood glucose to the levels observed in lean counterparts and stabilized these levels for the duration of the study ${ }^{[70]}$.

\section{Structure-activity relationship studies}

Small molecule ligands that interact and stabilize GPCRs are crucial for solving GPCR crystal structures. All of the current crystallized GPCRs were determined with the help of small molecule ligands. Of these structures, two class B GPCRs (GCGR and $\left.\mathrm{CRF}_{1} \mathrm{R}\right)$ possess the most abundant small molecule ligands in this family ${ }^{[12,13]}$. Small molecules facilitate the folding of GPCRs, establishing a stable state for recognition and receptor binding. Additionally, the unique properties of small molecules, as opposed to peptidic ligands, allow them to play key roles in the stabilization of GPCRs, including in aqueous solubility and hydrogen bonding. Clearly, the structural information gained from GPCRs promotes small molecule drug discovery such that structure-based virtual screening and drug design have now become an indispensable component of this process. Indeed, in the past decade, a number of SAR studies on class A GPCRs resulted in breakthrough discoveries on how these receptors look and work. These studies greatly increased our understanding of the molecular mechanisms of receptor binding and activation and have enabled structure- 
neg

www.nature.com/aps

Yang DH et al

1038

Table 2. Small molecule modulators for glucagon receptors.

№ Chemical structure

10

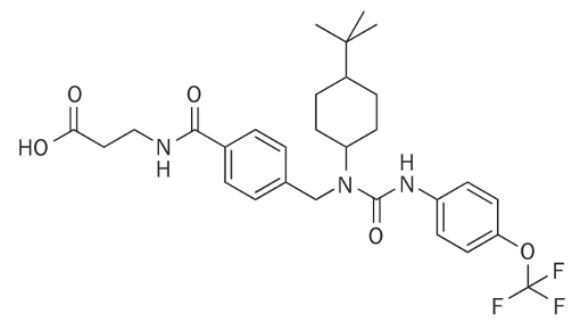

11

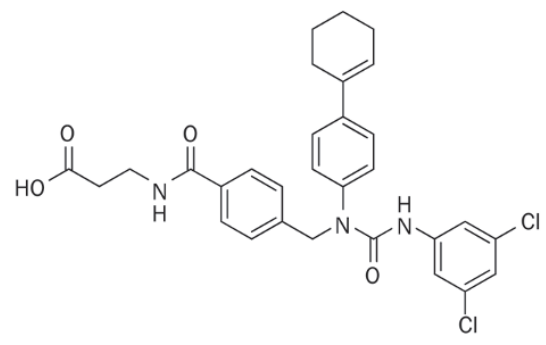

12

(L-168049)

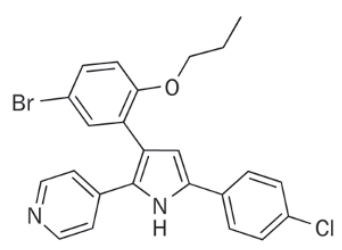

13

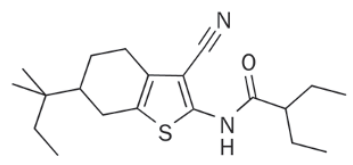

14

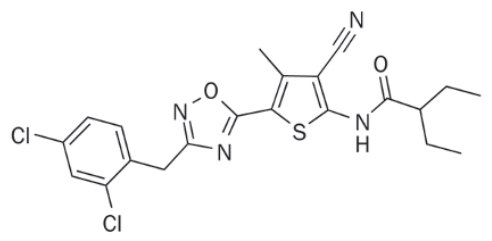

15

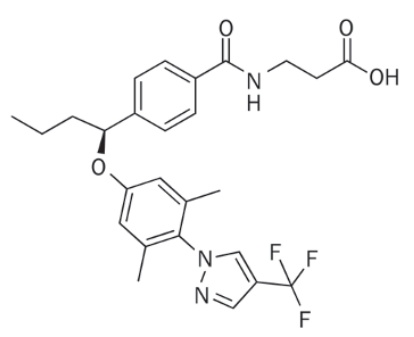

Selective antagonist $\mathrm{IC}_{50}=3.7 \mathrm{nmol} / \mathrm{L}$

Antagonist $\mathrm{IC}_{50}=181 \mathrm{nmol} / \mathrm{L}$

[66]

Antagonist $\mathrm{IC}_{50}=89 \mathrm{nmol} / \mathrm{L}$

[66]

Selective antagonist

[67]

(To be continued)

Acta Pharmacologica Sinica 
<smiles>O=C(O)CCNC(=O)c1ccc([C@H]2CCC[C@H]2c2cnc(-c3ccc(C(F)(F)F)cc3)nc2)cc1</smiles>

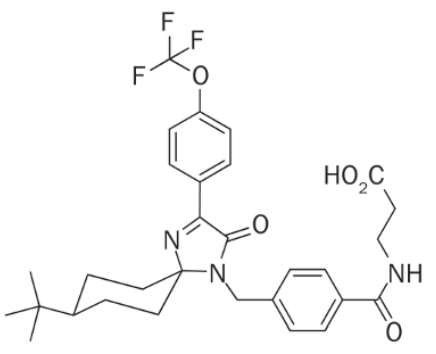

18

(SCH 900822)

19 (MK-0893)<smiles>CC(C)(C)CC[C@H](c1ccc(C(=O)NCc2nn[nH]n2)cc1)N1C(=O)C(c2cc(Cl)cc(Cl)c2)=NC12CCCC(C(C)(C)C)CC2</smiles><smiles>COc1ccc2cc(-c3cc(-c4cc(Cl)cc(Cl)c4)nn3C(C)c3ccc(C(=O)NCCC(=O)O)cc3)ccc2c1</smiles>

Selective antagonist

[69]

Selective antagonist

[69]

Selective and competitive antagonist
[70] based drug design ${ }^{[7]}$.

Class B GPCRs have large soluble N-terminal domains along with 7-TMDs. Using the ECD structures of $\mathrm{CRF}_{1} \mathrm{R}$ and corticotropin-releasing factor receptor $2 \alpha\left(C_{2 \alpha} R\right)$ with their four cognate ligands, Pal et al elucidated the structural basis of the differential ligand binding properties of these two recep-

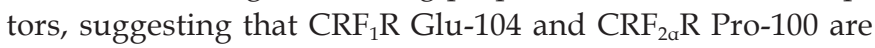
responsible for the selective recognition of $U_{c n} 2$ and Ucn3, respectively, by $\mathrm{CRF}_{2 \mathrm{a}} \mathrm{R}^{[23]}$. In the glucagon subfamily, the ECD structures of GCGR and GLP-1R in complex with antibodies or natural ligands have been reported ${ }^{[72]}$, showing that ligand specificity is primarily associated with the ECD while secondary recognition and signaling are mediated through the 7-TMDs ${ }^{[73-76]}$. The GLP-1R ECD structures in complex with exendin $9-39$ and GLP-1 clearly indicate the differences in molecular recognition between exendin-4 and GLP-1 that result in the higher binding affinity of exendin- $4^{[26]}$. The GCGR ECD structure was solved using a blocking antibody that targeted the ECD as an inverse agonist, which suggests that the ECD negatively regulates receptor activity independent of ligand binding. For the TMD structure, a particularly challenging problem is that there is a lack of small molecule compounds to stabilize the receptors ${ }^{[13]}$. Clearly, the crystal structure of fulllength GLP-1R will be a cornerstone for understanding the binding mechanism and for the design and development of small molecule ligands ${ }^{[40,72,77]}$.

Using the GCGR antagonist NNC0640, a derivative of compound 11, we were able to determine the 7-TMD crystal 
structure of human GCGR, thereby providing essential information for designing safer and more efficacious medications to combat metabolic disorders ${ }^{[12,68,69]}$. This breakthrough was made in parallel with the determination by a British team of the structure of $\mathrm{CRF}_{1} \mathrm{R}$ bound to the antagonist CP-376395 $5^{[13]}$. Both receptors are stabilized by truncated TMDs and fused to helper proteins. It is known that class B GPCRs share 7-TMD arrangements and alignments that are similar to those of class A GPCRs. A common feature of these two class B receptors is the existence of a deep ligand-binding pocket. They also show the following crucial differences: 1) GCGR has a long helix 8 at the $\mathrm{C}$-terminus, whereas crystallized $\mathrm{CRF}_{1} \mathrm{R}$ was truncated after TM7; 2) at the GCGR N-terminus, TM1 extends a 'stalk' into the extracellular space; and 3) the $C_{R F} R$ antagonist binds deep in the cavity and is distant from the orthosteric site, whereas the GCGR structure did not co-crystallize with NNC0640 $0^{[11]}$.

Combining previous structural information on ECD-ligand complexes with the GCGR and $\mathrm{CRF}_{1} \mathrm{R}$ TMD structures allowed us to construct a full receptor-ligand model, which accounted for the extensive interactions between peptide ligands and extracellular loops as well as the residues deep in the helical bundle, as reflected by mutagenesis and photo-cross-linking studies with different class B GPCRs ${ }^{[78]}$. The knowledge accumulated thus far offers a useful platform for the eventual determination of a full-length class B GPCR-ligand complex.

\section{Conclusion}

The development of small molecule ligands and the determination of crystal structures of glucagon subfamily members have increased our understanding of the molecular mechanisms governing receptor recognition and activation. Such insights are invaluable for the design and/or discovery of novel therapeutic agents targeting class B GPCRs.

\section{Acknowledgements}

This work was partially supported by the National Health and Family Planning Commission (2012ZX09304-011, 2013ZX09401003-005, 2013ZX09507001 and 2013ZX09507002), Shanghai Science and Technology Fund (12ZR1406900, 13DZ2290300 and 15DZ2291600), the CAS-Novo Nordisk Research Fund and the Thousand Talents Program in China. It was inspired by the international and interdisciplinary environments of the JSPS Asian CORE Program, "Asian Chemical Biology Initiative".

\section{References}

1 National Diabetes Statistics Report 2014. http://www.diabetes.org/ diabetes-basics/statistics/. Accessed Jan 29, 2015.

2 Xu Y, Wang L, He J, Bi Y, Li M, Wang T, et al. Prevalence and control of diabetes in Chinese adults. JAMA 2013; 310: 948-59.

3 Inzucchi SE, Bergenstal RM, Buse JB, Diamant M, Ferrannini E, Nauck $\mathrm{M}$, et al. Management of hyperglycemia in type 2 diabetes, 2015: a patient-centered approach: update to a position statement of the American Diabetes Association and the European Association for the Study of Diabetes. Diabetes Care 2015; 38: 140-9.

4 Lagerstrom MC, Schioth HB. Structural diversity of G protein-coupled receptors and significance for drug discovery. Nat Rev Drug Discov 2008; 7: 339-57.

5 Kobilka BK, Deupi X. Conformational complexity of G-protein-coupled receptors. Trends Pharmacol Sci 2007; 28: 397-406.

6 Lundstrom K. An overview on GPCRs and drug discovery: structurebased drug design and structural biology on GPCRs. Methods Mol Biol 2009; 552: 51-66.

7 Bjarnadottir TK, Gloriam DE, Hellstrand SH, Kristiansson H, Fredriksson $\mathrm{R}$, Schioth HB. Comprehensive repertoire and phylogenetic analysis of the $\mathrm{G}$ protein-coupled receptors in human and mouse. Genomics 2006; 88: 263-73.

8 Zhang X, Stevens RC, Xu F. The importance of ligands for G proteincoupled receptor stability. Trends Biochem Sci 2015; 40: 79-87.

9 Yin J, Mobarec JC, Kolb P, Rosenbaum DM. Crystal structure of the human OX2 orexin receptor bound to the insomnia drug suvorexant. Nature 2015; 519: 247-50.

10 Zhang D, Gao ZG, Zhang K, Kiselev E, Crane S, Wang J, et al. Two disparate ligand-binding sites in the human P2Y1 receptor. Nature 2015; 520: 317-21.

11 Hollenstein K, de Graaf C, Bortolato A, Wang MW, Marshall FH, Stevens RC. Insights into the structure of class B GPCRs. Trends Pharmacol Sci 2014; 35: 12-22.

12 Siu FY, He M, de Graaf C, Han GW, Yang D, Zhang Z, et al. Structure of the human glucagon class B G-protein-coupled receptor. Nature 2013; 499: 444-9.

13 Hollenstein K, Kean J, Bortolato A, Cheng RK, Dore AS, Jazayeri A, et al. Structure of class B GPCR corticotropin-releasing factor receptor 1. Nature 2013; 499: 438-43.

14 Gozes I, Divinsky I, Pilzer I, Fridkin M, Brenneman DE, Spier AD. From vasoactive intestinal peptide (VIP) through activity-dependent neuroprotective protein (ADNP) to NAP: a view of neuroprotection and cell division. J Mol Neurosci 2003; 20: 315-22.

15 Delgado M, Pozo D, Ganea D. The significance of vasoactive intestinal peptide in immunomodulation. Pharmacol Rev 2004; 56: 249-90.

16 Campbell RM, Bongers J, Felix AM. Rational design, synthesis, and biological evaluation of novel growth hormone releasing factor analogues. Biopolymers 1995; 37: 67-88.

17 Brubaker PL. Incretin-based therapies: mimetics versus protease inhibitors. Trends Endocrinol Metab 2007; 18: 240-5.

18 Jeppesen PB. Glucagon-like peptide-2: update of the recent clinical trials. Gastroenterology 2006; 130: S127-31.

19 Epstein S. Is cortical bone hip? What determines cortical bone properties? Bone 2007; 41: S3-8.

20 Gilligan PJ, Li YW. Corticotropin-releasing factor antagonists: recent advances and exciting prospects for the treatment of human diseases. Curr Opin Drug Discov Devel 2004; 7: 487-97.

21 Fortin JP, Zhu Y, Choi C, Beinborn M, Nitabach MN, Kopin AS. Membrane-tethered ligands are effective probes for exploring class B1 G protein-coupled receptor function. Proc Natl Acad Sci U S A 2009; 106: 8049-54.

22 Pioszak AA, Parker NR, Suino-Powell K, Xu HE. Molecular recognition of corticotropin-releasing factor by its G-protein-coupled receptor CRFR1. J Biol Chem 2008; 283: 32900-12.

23 Pal K, Swaminathan K, Xu HE, Pioszak AA. Structural basis for hormone recognition by the human CRFR2\{alpha\} G protein-coupled receptor. J Biol Chem 2010; 285: 40351-61.

24 Kumar S, Pioszak A, Zhang C, Swaminathan K, Xu HE. Crystal structure of the PAC1R extracellular domain unifies a consensus fold for hormone recognition by class B G-protein coupled receptors. PLoS One 2011; 6: e19682.

25 Grace CR, Perrin MH, DiGruccio MR, Miller CL, Rivier JE, Vale WW, 
et al. NMR structure and peptide hormone binding site of the first extracellular domain of a type B1 G protein-coupled receptor. Proc Natl Acad Sci U S A 2004; 101: 12836-41.

26 Underwood CR, Garibay P, Knudsen LB, Hastrup S, Peters GH, Rudolph $\mathrm{R}$, et al. Crystal structure of glucagon-like peptide-1 in complex with the extracellular domain of the glucagon-like peptide-1 receptor. J Biol Chem 2010; 285: 723-30.

27 Koth CM, Murray JM, Mukund S, Madjidi A, Minn A, Clarke HJ, et al. Molecular basis for negative regulation of the glucagon receptor. Proc Natl Acad Sci U S A 2012; 109: 14393-8.

28 ter Haar E, Koth CM, Abdul-Manan N, Swenson L, Coll JT, Lippke JA, et al. Crystal structure of the ectodomain complex of the CGRP receptor, a class-B GPCR, reveals the site of drug antagonism. Structure 2010; 18: 1083-93.

29 Sun C, Song D, Davis-Taber RA, Barrett LW, Scott VE, Richardson PL, et al. Solution structure and mutational analysis of pituitary adenylate cyclase-activating polypeptide binding to the extracellular domain of PAC1-RS. Proc Natl Acad Sci U S A 2007; 104: 7875-80.

30 Bortolato A, Dore AS, Hollenstein K, Tehan BG, Mason JS, Marshall $\mathrm{FH}$. Structure of class B GPCRs: new horizons for drug discovery. $\mathrm{Br} J$ Pharmacol 2014; 171: 3132-45.

31 Parthier C, Reedtz-Runge S, Rudolph R, Stubbs MT. Passing the baton in class B GPCRs: peptide hormone activation via helix induction? Trends Biochem Sci 2009; 34: 303-10.

$32 \mathrm{Pal}$ K, Melcher K, Xu HE. Structure and mechanism for recognition of peptide hormones by class B G-protein-coupled receptors. Acta Pharmacol Sin 2012; 33: 300-11.

33 Holst JJ. Treatment of type 2 diabetes mellitus with agonists of the GLP-1 receptor or DPP-IV inhibitors. Expert Opin Emerg Drugs 2004; 9: 155-66.

34 Hansen LH, Abrahamsen N, Nishimura E. Glucagon receptor mRNA distribution in rat tissues. Peptides 1995; 16: 1163-6.

35 Burcelin R, Katz EB, Charron MJ. Molecular and cellular aspects of the glucagon receptor: role in diabetes and metabolism. Diabetes Metab 1996; 22: 373-96.

36 Abrahamsen N, Lundgren K, Nishimura E. Regulation of glucagon receptor $\mathrm{mRNA}$ in cultured primary rat hepatocytes by glucose and cAMP. J Biol Chem 1995; 270: 15853-7.

37 Moens K, Flamez D, Van Schravendijk C, Ling Z, Pipeleers D, Schuit F. Dual glucagon recognition by pancreatic beta-cells via glucagon and glucagon-like peptide 1 receptors. Diabetes 1998; 47: 66-72.

38 Gelling RW, Du XQ, Dichmann DS, Romer J, Huang H, Cui L, et al. Lower blood glucose, hyperglucagonemia, and pancreatic alpha cell hyperplasia in glucagon receptor knockout mice. Proc Natl Acad Sci U S A 2003; 100: 1438-43.

39 Bullock BP, Heller RS, Habener JF. Tissue distribution of messenger ribonucleic acid encoding the rat glucagon-like peptide-1 receptor. Endocrinology 1996; 137: 2968-78.

40 Runge S, Schimmer S, Oschmann J, Schiodt CB, Knudsen SM, Jeppesen CB, et al. Differential structural properties of GLP-1 and exendin- 4 determine their relative affinity for the GLP-1 receptor $\mathrm{N}$-terminal extracellular domain. Biochemistry 2007; 46: 5830-40.

41 Lund A, Knop FK, Vilsboll T. Emerging GLP-1 receptor agonists. Expert Opin Emerg Drugs 2011; 16: 607-18.

42 Koole C, Savage EE, Christopoulos A, Miller L, Sexton PM, Wootten D. Minireview: Signal bias, allosterism, and polymorphic variation at the GLP-1R: implications for drug discovery. Mol Endocrinol 2013; 27 : 1234-44.

43 Chen D, Liao J, Li N, Zhou C, Liu Q, Wang G, et al. A nonpeptidic agonist of glucagon-like peptide 1 receptors with efficacy in diabetic db/db mice. Proc Natl Acad Sci U S A 2007; 104: 943-8.
44 Trujillo JM, Nuffer W. GLP-1 receptor agonists for type 2 diabetes mellitus: recent developments and emerging agents. Pharmacotherapy 2014; 34: 1174-86.

45 Shi X, Zhou F, Li X, Chang B, Li D, Wang Y, et al. Central GLP-2 enhances hepatic insulin sensitivity via activating PI3K signaling in POMC neurons. Cell Metab 2013; 18: 86-98.

46 Bahrami J, Longuet C, Baggio LL, Li K, Drucker DJ. Glucagon-like peptide-2 receptor modulates islet adaptation to metabolic stress in the ob/ob mouse. Gastroenterology 2010; 139: 857-68.

47 Yamazaki K, Terauchi H, lida D, Fukumoto H, Suzuki S, Kagaya T, et al. Ago-allosteric modulators of human glucagon-like peptide 2 receptor. Bioorg Med Chem Lett 2012; 22: 6126-35.

48 Gaudin-Audrain C, Irwin N, Mansur S, Flatt PR, Thorens B, Basle M, et al. Glucose-dependent insulinotropic polypeptide receptor deficiency leads to modifications of trabecular bone volume and quality in mice. Bone 2013; 53: 221-30.

49 Lennox RR, Moffett C, Porter DW, Irwin N, Gault VA, Flatt PR. Effects of glucose-dependent insulinotropic polypeptide receptor knockout and a high-fat diet on cognitive function and hippocampal gene expression in mice. Mol Med Rep 2015; 12: 1544-8.

50 Seino Y, Fukushima M, Yabe D. GIP and GLP-1, the two incretin hormones: Similarities and differences. J Diabetes Investig 2010; 1: 8-23.

51 Ahlqvist E, Osmark P, Kuulasmaa T, Pilgaard K, Omar B, Brons C, et al. Link between GIP and osteopontin in adipose tissue and insulin resistance. Diabetes 2013; 62: 2088-94.

52 Tibaduiza EC, Chen C, Beinborn M. A small molecule ligand of the glucagon-like peptide 1 receptor targets its amino-terminal hormone binding domain. J Biol Chem 2001; 276: 37787-93.

53 Wootten D, Simms J, Koole C, Woodman OL, Summers RJ, Christopoulos A, et al. Modulation of the glucagon-like peptide-1 receptor signaling by naturally occurring and synthetic flavonoids. J Pharmacol Exp Ther 2011; 336: 540-50.

54 Knudsen LB, Kiel D, Teng M, Behrens C, Bhumralkar D, Kodra JT, et al. Small-molecule agonists for the glucagon-like peptide 1 receptor. Proc Natl Acad Sci U S A 2007; 104: 937-42.

55 Sloop KW, Willard FS, Brenner MB, Ficorilli J, Valasek K, Showalter $A D$, et al. Novel small molecule glucagon-like peptide-1 receptor agonist stimulates insulin secretion in rodents and from human islets. Diabetes 2010; 59: 3099-107.

56 Rao M. Ligands for the GLP-1 receptor and methods for discovery thereof. PCT/US2009/039905.

57 Polisetti DR, Benjamin E, Quada JC, Thorsteinsson T. Solid compositions comprising an oxadiazoanthracene compound and methods of making and using the same. PCT/US2010/047661.

58 Mjallli AM, Polisetti DR, Yokum TS, Kalpathy S, Guzel M, Behme C, et al. Oxadiazoanthracene compounds for the treatment of diabetes. PCT/US2009/036333.

59 Polisett DR, Benjamin E, Quada JC, Thorsteinsson T. Solid composition comprising an oxadiazoanthracene compound and methods of making and using the same. W02011/031620

60 Liu Q, Li N, Yuan Y, Lu H, Wu X, Zhou C, et al. Cyclobutane derivatives as novel nonpeptidic small molecule agonists of glucagon-like peptide-1 receptor. J Med Chem 2012; 55: 250-67.

$61 \mathrm{He} \mathrm{M,} \mathrm{Su} \mathrm{H,} \mathrm{Gao} \mathrm{W,} \mathrm{Johansson} \mathrm{SM,} \mathrm{Liu} \mathrm{Q,} \mathrm{Wu} \mathrm{X,} \mathrm{et} \mathrm{al.} \mathrm{Reversal}$ of obesity and insulin resistance by a non-peptidic glucagon-like peptide-1 receptor agonist in diet-induced obese mice. PLoS One 2010; 5: e14205.

62 Su H, He M, Li H, Liu Q, Wang J, Wang Y, et al. Boc5, a non-peptidic glucagon-like peptide-1 receptor agonist, invokes sustained glycemic control and weight loss in diabetic mice. PLoS One 2008; 3: e2892. 
63 He M, Guan N, Gao WW, Liu Q, Wu XY, Ma DW, et al. A continued saga of Boc5, the first non-peptidic glucagon-like peptide-1 receptor agonist with in vivo activities. Acta Pharmacol Sin 2012; 33: 148-54.

64 Lau J, Behrens C, Sidelmann UG, Knudsen LB, Lundt B, Sams C, et al. New beta-alanine derivatives are orally available glucagon receptor antagonists. J Med Chem 2007; 50: 113-28.

65 Cascieri MA, Koch GE, Ber E, Sadowski SJ, Louizides D, de Laszlo SE, et al. Characterization of a novel, non-peptidyl antagonist of the human glucagon receptor. J Biol Chem 1999; 274: 8694-7.

66 Duffy JL, Kirk BA, Konteatis Z, Campbell EL, Liang R, Brady EJ, et al. Discovery and investigation of a novel class of thiophene-derived antagonists of the human glucagon receptor. Bioorg Med Chem Lett 2005; 15: 1401-5.

67 Guzman-Perez A, Pfefferkorn JA, Lee EC, Stevens BD, Aspnes GE, Bian J, et al. The design and synthesis of a potent glucagon receptor antagonist with favorable physicochemical and pharmacokinetic properties as a candidate for the treatment of type 2 diabetes mellitus. Bioorg Med Chem Lett 2013; 23: 3051-8.

68 Lee EC, Tu M, Stevens BD, Bian J, Aspnes G, Perreault C, et al. Identification of a novel conformationally constrained glucagon receptor antagonist. Bioorg Med Chem Lett 2014; 24: 839-44.

69 DeMong D, Dai X, Hwa J, Miller M, Lin SI, Kang L, et al. The discovery of $\mathrm{N}$-((2H-tetrazol-5-yl)methyl)-4-((R)-1-((5r,8R)-8-(tert-butyl)-3(3,5-dichlorophenyl)-2-oxo-1,4-diazaspiro[4.5]dec-3-en-1-yl)-4,4dimethylpentyl)benzamide ( $\mathrm{SCH}$ 900822): a potent and selective glucagon receptor antagonist. J Med Chem 2014; 57: 2601-10.

70 Xiong Y, Guo J, Candelore MR, Liang R, Miller C, Dallas-Yang Q, et al. Discovery of a novel glucagon receptor antagonist $N-[(4-\{(1 S)-1-[3-(3$, 5-dichlorophenyl)-5-(6-methoxynaphthalen-2-yl)-1H-pyrazol-1-yl]ethyl\} phenyl)carbonyl]-beta-alanine (MK-0893) for the treatment of type II diabetes. J Med Chem 2012; 55: 6137-48.

71 Katritch V, Cherezov V, Stevens RC. Structure-function of the G protein-coupled receptor superfamily. Annu Rev Pharmacol Toxicol
2013; 53: 531-56.

72 Underwood CR, Garibay P, Knudsen LB, Hastrup S, Peters GH, Rudolph $\mathrm{R}$, et al. Crystal structure of glucagon-like peptide-1 in complex with the extracellular domain of the glucagon-like peptide-1 receptor. J Biol Chem 2010; 285: 723-30.

73 Pioszak AA, Xu HE. Molecular recognition of parathyroid hormone by its G protein-coupled receptor. Proc Natl Acad Sci U S A 2008; 105 : 5034-9.

74 West GM, Willard FS, Sloop KW, Showalter AD, Pascal BD, Griffin PR. Glucagon-like peptide-1 receptor ligand interactions: structural cross talk between ligands and the extracellular domain. PLoS One 2014; 9: e105683.

75 Donnelly $\mathrm{D}$. The structure and function of the glucagon-like peptide-1 receptor and its ligands. Br J Pharmacol 2012; 166: 27-41.

76 Parthier C, Kleinschmidt M, Neumann P, Rudolph R, Manhart S, Schlenzig D, et al. Crystal structure of the incretin-bound extracellular domain of a G protein-coupled receptor. Proc Natl Acad Sci U S A 2007; 104: 13942-7.

77 Runge S, Thogersen H, Madsen K, Lau J, Rudolph R. Crystal structure of the ligand-bound glucagon-like peptide-1 receptor extracellular domain. J Biol Chem 2008; 283: 11340-7.

78 Coin I, Katritch V, Sun T, Xiang Z, Siu FY, Beyermann M, et al. Genetically encoded chemical probes in cells reveal the binding path of urocortin-I to CRF class B GPCR. Cell 2013; 155: 1258-69.

This work is licensed under the Creative Commons Attribution-NonCommercial-No Derivative Works 3.0 Unported License. To view a copy of this license, visit http://creativecommons.org/licenses/ by-nc-nd/3.0/ 